\title{
Promoçâo das Práticas Corporais/ Atividade Física nos programas de governos presidenciais do Brasil (2018): diferentes caminhos, diferentes intencionalidades
}

\author{
I ${ }^{1}$ Paulo Henrique Guerra, ${ }^{2}$ Douglas Roque Andrade, ${ }^{3}$ Mathias Roberto Loch I
}

Resumo: Este estudo buscou identificar estratégias e intencionalidades relativas à promoção das práticas corporais / atividade física (PCAF) nas propostas de governo (PG) presidenciais (2018). Em posse das PG, realizamos leituras e buscas por termos relacionados a temática das PCAF. Para a análise dos dados, usamos elementos da análise de conteúdo temática. Em apenas seis (46,2\%) das 13 PG deferidas foram encontradas mençóes às PCAF. Em cinco PG identificamos estratégias relacionadas ao esporte de recreação e em quatro às PCAF no ambiente escolar. Quanto às intencionalidades, percebemos desde aquelas mais ligadas à melhoria de aspectos clínicos de saúde e enfrentamento ao uso de drogas até as que assumem o entendimento do acesso das PCAF como direito de todos. Concluímos que o acesso às PCAF ainda não é reconhecido enquanto direito de todas as pessoas, uma vez que mais da metade das PG sequer apresenta menção ao tema e que as PG que abordaram esta temática diferiram bastante tanto em relação a suas estratégias e intencionalidades para sua promoção, indicando que o discurso sobre a promoção das PCAF pode servir a diferentes projetos de país, sendo necessária uma análise criteriosa a respeito de seus caminhos e intencionalidades.

> Palavras-chave: atividades motoras; política pública; democracia; programas de governo.

\author{
1 Universidade Federal da \\ Fronteira Sul. Chapecó-SC, Brasil \\ (paulo.guerra@uffs.edu.br). \\ ORCID: 0000-0003-4239-0716 \\ 2 Universidade de São Paulo. \\ São Paulo-SP, Brasil (douglas \\ andrade@usp.br). \\ ORCID: 0000-0001-5135-582X \\ ${ }^{3}$ Universidade Estadual de \\ Londrina. Londrina-PR, Brasil \\ (mathias@uerl.br). \\ ORCID: 0000-0002-2680-4686
}

Recebido em: 23/08/2019 Aprovado em: 03/03/2020 Revisado em: 27/07/2021 


\section{Introdução}

A Lei no 9.504, de 30 de setembro de 1997 (BRASIL, 1997), que estabelece as normas para eleição no Brasil, exige que seja feito o registro das Propostas de Governo (PG) no Tribunal Superior Eleitoral (TSE) dos(as) candidatos(as) aos cargos executivos. Em sendo documentos oficiais, as PG devem - ou deveriam - servir de base para a análise dos eleitores sobre as açôes e intençôes de cada candidato(a) em relação à diversos temas de interesse coletivo, como educação, segurança pública e saúde, assim como oferecer indícios sobre o direcionamento das políticas públicas que serão adotadas pelo(a) candidato(a) eleito(a). Na literatura, são observados estudos que buscam identificar e analisar o conteúdo de PG, em temáticas ambientais (SORIANO et al., 2013; BARROS, 2017; TRAJANO; MARQUES; MARQUEZAN, 2017) e políticas sociais (MATIAS; BARROS, 2019).

Apesar do importante papel das Práticas Corporais e Atividade Física (PCAF) no desenvolvimento humano, inclusive em função da sua relação com indicadores de saúde, qualidade de vida, cognição e produtividade (PNUD, 2017), entre outros aspectos da vida humana, ainda pouco se discute sobre sua inserção nas PG brasileiras. No âmbito da saúde, o Brasil é reconhecido pela introdução de políticas públicas de promoção das PCAF, implementadas desde a segunda metade da década de 1990 (MATSUDO et al., 2002; BRASIL, 2013a; 2013b; 2014; 2019), com considerável atenção no debate acadêmico (AMORIM et al., 2013; HALLAL, 2014; MALTA et al., 2014; CARVALHO; NOGUEIRA, 2016), assim como pelas suas contribuições científicas e posição de liderança em iniciativas internacionais de vigilância (ex. Observatório Global de Atividade Física) e de formação de redes (ex. Rede Agita Mundo e da Rede de Atividade Física das Américas).

Mesmo reconhecendo as diferenças conceituais entre as vertentes "práticas e corporais" e "atividade física" (DAMICO; KNUTH, 2014), o presente estudo busca integrá-las numa única perspectiva, no sentido de favorecer seu debate de forma ampliada. Vale mencionar que alguns documentos e políticas usam a terminologia "Práticas Corporais e Atividades Físicas", como é o caso, por exemplo, da Política Nacional de Promoção da Saúde (BRASIL, 2014).

Contudo, é prudente mencionar que as PCAF não são uma questão exclusiva do setor saúde e, há de se considerar que, mesmo dentro deste, diversos "olhares" são possíveis, de modo que as intenções (ou finalidades) relacionadas 
à promoção das PCAF podem divergir, de acordo com a visão dos diferentes "projetos" de governo/ vertentes políticas. Isso pode ser melhor compreendido se considerarmos que a Educação Física - que apesar de não ser a única área vinculada à promoção das PCAF é certamente a mais diretamente relacionada - no Brasil foi e é influenciada por diversas abordagens e perspectivas, como por exemplo: higienista, militar, esportiva e científica (BRACHT, 2000; CASTELANI FILHO, 1988; MANOEL; CARVALHO, 2011). Não é objetivo do presente texto discorrer ou buscar consensos sobre a questão historiográfica destas abordagens e perspectivas, mas apontar que a práxis em Educação Física foi e ainda é impactada por distintas influências.

Nesse sentido, visto que uma análise das PG pode contribuir para com o direcionamento da necessária defesa (advocacy) da promoção das PCAF na agenda política das cidades, estados e no governo federal, o objetivo do presente estudo foi identificar e analisar comparativamente os discursos sobre estratégias e intencionalidades relativas à promoção das PCAF no país, nas PG dos(as) candidatos(as) à presidência da República do Brasil, registradas no TSE, na eleição realizada em 2018 (para o quadriênio 2019-2022).

\section{Métodos}

Para tanto, foi conduzida uma pesquisa documental descritiva e analítica. Para Sá-Silva, Almeida e \& Guindani (2009), a pesquisa documental é um procedimento que se utiliza de métodos e técnicas para a apreensão, compreensão e análise de documentos dos mais variados tipos.

A escolha dos documentos a serem analisados se deu de maneira intencional, considerando o objetivo do estudo, que definiu a priori que os documentos seriam as PG dos candidatos e candidatas à presidência da república do Brasil na eleição de 2018. Assim, no dia 10 de outubro de 2018, após a realização do primeiro turno das eleiçôes, identificamos, no sítio eletrônico do TSE, ${ }^{1}$ as 13 PG deferidas dos(as) candidatos(as) ao cargo de presidente da república (quadriênio 2019-2022) (quadro 1). A opção de organização dos arquivos após a realização do primeiro turno se deu pela garantia de termos as versôes finais (definitivas) das PG deferidas. Da mesma forma, também foram recuperadas após o pleito as PG dos candidatos que participaram do segundo turno, de modo que possíveis mudanças fossem identificadas. 
Inicialmente, a intenção era focar este estudo nos termos Práticas Corporais e Atividade Física. No entanto, a leitura inicial das PG mostrou que as menções específicas a estes termos eram inexistentes na maioria das propostas, enquanto outros termos relacionados, especialmente "esporte", estavam presentes, mesmo que muitas vezes com um sentido bastante genérico, próximos inclusive do entendimento de "atividade física" e não em seu sentido mais formal, que mesmo sendo um termo com diversos significados, é entendido normalmente em um sentido mais restrito, que envolve aspectos como a existência de regras institucionalizadas e alcance de um determinado desempenho/ rendimento entre indivíduos ou grupos (GONZÁLES; FENSTERSEIFER, 2008) - características estas não necessariamente compartilhadas por todas as PCAF.

No intuito de evitar a perda de informação relevante, para além das leituras integrais das PG, também buscou-se encontrar nos documentos, com ajuda da função "localizar" no software de leitura, os seguintes termos: "educação física", "esporte”, "atividade(s) física(s)", "prática(s) corporal(is)", "sedentário(ismo)", "mobilidade", "ciclovia/ ciclofaixa", "bicicleta" e "lazer". Estes termos foram escolhidos por conveniência, a partir da experiência acumulada dos autores na temática. Operacionalmente, passamos a considerar estes termos como sendo relacionados à "temática das PCAF", inclusive porque não foi objetivo do estudo o foco em aspectos mais conceituais ligados a estes termos.

Nossa abordagem inicial foi meramente descritiva e quantitativa, com objetivo de levantar o número de vezes que aparecia, em cada PG, termos ligados à temática das PCAF.

Após esta etapa, utilizamos, para a análise dos documentos, elementos da análise de conteúdo temática, seguindo os passos apresentados por GOMES (2010) especificamente a partir das etapas de pré-análise, exploração do material e tratamento dos resultados/inferência/interpretação. Evidentemente estes procedimentos foram realizados com certa flexibilidade, no sentido de que o processo de análise qualitativa não é totalmente linear, como destaca SOUZA (2019), quando afirma que a flexibilidade é um aspecto fundamental à pesquisa qualitativa e o processo de análise requer algum movimento de vaivém, conforme as necessidades vão aparecendo ao longo do processo.

$\mathrm{Na}$ primeira etapa (pré-análise), buscamos realizar uma análise compreensiva inicial do material selecionado, isto é, das partes das PG que tinham relação com 
a temática do nosso interesse. Esta etapa possibilitou uma visão mais ampliada do conjunto de dados em análise e permitiu perceber as diferentes estratégias e intencionalidades das PG que apresentavam algo sobre a temática das PCAF.

Por meio da exploração do material (segunda etapa), buscamos identificar nas PG as estratégias para a promoção das PCAF e as classificamos em três categorias: I) Açôes, identificadas como atividades pontuais e isoladas; II) Programas, definida para os fins deste trabalho como um conjunto de açóes e atividades com a descrição de objetivos, metas e procedimentos ou III) Políticas Públicas, como um conjunto de programas, ações e decisôes tomadas pelos governos com a participação, direta ou indireta, de entes públicos ou privados que visam assegurar determinado direito assegurados na Constituição, podendo ser uma política de governo ou de Estado, bem como as intencionalidades de cada proposta ou, de maneira mais ampla, das PG.

A partir dessa exploração do material, compreendeu-se que seria impossível estabelecer em todas as estratégias a sua respectiva intencionalidade. Em alguns casos, as estratégias de fato vinham "acompanhadas" da sua respectiva intencionalidade, mas em outros casos havia um texto introdutório sobre as intencionalidades e depois se apresentava um conjunto de estratégias - ou mesmo não havia definição das intencionalidades de algumas estratégias.

Assim, ao passo que iniciamos o tratamento dos resultados e sua respectiva interpretação, consideramos mais adequado apresentar de maneira separada as estratégias (quadro 2) e as intencionalidades (quadro 3) em relação à temática das PCAF nas PG. Para facilitar a compreensão das intencionalidades que eram vinculadas às estratégias (como em muitos casos a estratégia e a intencionalidade estavam apresentadas em sequência), optamos por numerar as propostas de cada PG, colocando-se a primeira letra do(a) candidato(a) e o respectivo número da proposta, sendo possível de avaliar, quando estava mencionado na PG, a estratégia e sua respectiva intencionalidade. Por exemplo: a proposta $\mathrm{C} 1$ do candidato Ciro Gomes apresentada no quadro 2, tem a sua intencionalidade apresentada no quadro 3 e é possível vincular a estratégia com sua respectiva intencionalidade a partir do código (C1), que aparece em ambos os quadros. Nos casos em que a PG apresentava intencionalidade(s) na temática das PCAF, mas esta(s) não ficava(m) explicitamente ligada(s) à alguma estratégia, colocamos que a intencionalidade não estava relacionada à alguma estratégia específica (nr: "não-relacionada"). 
Vale ainda mencionar que consideramos os nomes registrados de cada candidato(a) para aparecer na urna e seguimos a ordem alfabética destes nomes para a apresentação dos resultados nos quadros. Além disso, buscamos reproduzir literalmente os textos apresentados nas PG, usando aspas para tanto nos quadros e, sempre que possível, no texto.

\section{Resultados}

Em seis $(46,2 \%)$ das 13 PG analisadas foram encontradas mençôes relacionadas a, pelo menos, um dos termos pesquisados (COLIGAÇÃO BRASIL ACIMA DE TUDO, DEUS ACIMA DE TODOS, 2018; COLIGAÇÃO BRASIL SOBERANO, 2018; COLIGAÇÃO O POVO FELIZ DE NOVO, 2018; COLIGAÇÃO UNIDOS PARA TRANSFORMAR O BRASIL, 2018; COLIGAÇÃO VAMOS SEM MEDO DE MUDAR O BRASIL, 2018; PARTIDO DEMOCRACIA CRISTÁ, 2018) (quadro 1). Nestas seis PG, identificamos 37 estratégias no tema PCAF, com maior frequência nas PG de Guilherme Boulos (COLIGAÇÃO VAMOS SEM MEDO DE MUDAR O BRASIL, 2018) ( $\mathrm{n}=19)$ e Fernando Haddad (COLIGAÇÃO O POVO FELIZ DE NOVO, 2018) $(\mathrm{n}=9)$.

Quadro 1. Relação de candidaturas deferidas ao cargo de Presidente da República, Brasil, 2018 e número de mençóes ao tema Práticas Corporais/Atividade Física

\begin{tabular}{|llc|}
\hline Candidato(a) & Partido(s) envolvido(s) na Proposta de Governo & $\begin{array}{c}\text { Número de Mençóes } \\
\text { na temática "Práticas } \\
\text { Corporais/Atividade Física" }\end{array}$ \\
\hline Álvaro Dias & $\begin{array}{l}\text { Podemos; Partido Social Cristão; Partido } \\
\text { Republicano Progressista e Partido Trabalhista } \\
\text { Cristão }\end{array}$ & 0 \\
\hline Cabo Daciolo & Patriota & 0 \\
\hline Ciro Gomes & Partido Democrático Trabalhista; Avante & 2 \\
\hline Eymael & Democracia Cristá & 2 \\
\hline Fernando Haddad & $\begin{array}{l}\text { Partido dos Trabalhadores; Partido Comunista do } \\
\text { Brasil e Partido Republicano da Ordem Social }\end{array}$ & 9 \\
\hline
\end{tabular}

continua... 


\begin{tabular}{|lll|}
\hline Candidato(a) ${ }^{\mathbf{a}}$ & Partido(s) envolvido(s) na Proposta de Governo & $\begin{array}{l}\text { Número de Mençóes } \\
\text { na temática "Práticas } \\
\text { Corporais/Atividade Física" }\end{array}$ \\
\hline Geraldo Alckmin & $\begin{array}{l}\text { Partido da Social-Democracia Brasileira; } \\
\text { Progressistas; Partido Trabalhista Brasileiro; } \\
\text { Partido Social Democrático; Partido Republicano } \\
\text { Brasileiro; Partido da República, Democratas; } \\
\text { Solidariedade e Partido Popular Socialista }\end{array}$ & 0 \\
\hline Guilherme Boulos & $\begin{array}{l}\text { Partido Socialismo e Liberdade e Partido } \\
\text { Comunista Brasileiro }\end{array}$ & 19 \\
\hline Henrique Meirelles & $\begin{array}{l}\text { Movimento Democrático Brasileiro e Partido } \\
\text { Humanista da Solidariedade }\end{array}$ & 0 \\
\hline Jair Bolsonaro & $\begin{array}{l}\text { Partido Social Liberal; Partido Renovador } \\
\text { Trabalhista Brasileiro }\end{array}$ & 1 \\
\hline João Amoêdo & Partido Novo & 0 \\
\hline João Goulart Filho & Partido Pátria Livre & 4 \\
\hline Marina Silva & Rede Sustentabilidade e Partido Verde & 0 \\
\hline Vera & Partido Socialista dos Trabalhadores Unificado & 0 \\
\hline
\end{tabular}

Legenda: ${ }^{a}$ : nome registrado para aparecer na urna

Quanto aos tipos de estratégias, identificou-se maior presença de açôes ( $\mathrm{n}=32$; $86 \%)$, seguidas de políticas $(\mathrm{n}=4 ; 11 \%)$ e programas $(\mathrm{n}=1 ; 3 \%)$ (quadro 2 ).

Estratégias relacionadas ao esporte recreativo foram as mais frequentes, presentes em cinco das seis PG que apresentaram estratégias para o tema PCAF (1315,17,18) (quadro 2). Em um sentido ampliado, a PG de Eymael propóe a criação do "plano nacional de apoio ao esporte amador competitivo" (E1) (PARTIDO DEMOCRACIA CRISTÁ, 2018), a PG de Fernando Haddad menciona a "integração [...] com as demais políticas públicas" (F3) (COLIGAÇÃO O POVO FELIZ DE NOVO, 2018) e a PG de Guilherme Boulos (COLIGAÇÃO VAMOS SEM MEDO DE MUDAR O BRASIL, 2018) aponta para açôes que partem desde a criação do "Ministério do Esporte e Lazer" (G7) até o debate do tema no contexto da "democracia direta" (G14), com "fundo público descentralizado" (G16) e direcionamento dos "gastos orçamentários prioritariamente para a garantia do esporte e lazer como direito" (G17), assim como o estabelecimento de "mecanismos de monitoramento e avaliação das políticas [...] garantindo 
transparência e controle social" (G13) (COLIGAÇÃO VAMOS SEM MEDO DE MUDAR O BRASIL, 2018).

A promoção sistêmica do esporte (envolvendo suas distintas dimensóes) foi observada nas PG de Fernando Haddad (F6) (COLIGAÇÃO O POVO FELIZ DE NOVO, 2018) e Guilherme Boulos (G2) (COLIGAÇÃO VAMOS SEM MEDO DE MUDAR O BRASIL, 2018). Nestes dois documentos, também encontramos estratégias voltadas à formação de profissionais e recursos (F7, G11 e G12). No mesmo sentido, a PG de Guilherme Boulos propõe outras açôes, como o "Diagnóstico Nacional" (G8), a realização bianual da "Conferência Nacional de Esporte e Lazer" (G9), o fortalecimento da rede CEDES (G10) e a criação do "Programa de Apoio às Pesquisas" no tema (G11) (COLIGAÇÃO VAMOS SEM MEDO DE MUDAR O BRASIL, 2018) (quadro 2).

Estratégias voltadas ao ambiente escolar foram observadas em quatro PG (1315,18) (quadro 2). Não diferente das mençôes ao esporte de recreação, observamos estratégias distintas, como "implementação e qualificação do esporte nas escolas" (C1) (COLIGAÇÃO BRASIL SOBERANO, 2018), "promoção do esporte escolar" (F1) (COLIGAÇÃO O POVO FELIZ DE NOVO, 2018), promoção de "jogos, torneios e competiçôes entre escolas" (G5) (COLIGAÇÃO VAMOS SEM MEDO DE MUDAR O BRASIL, 2018), criação do "Centro de Desenvolvimento da Educação Física Escolar” (G11) (COLIGAÇÃO VAMOS SEM MEDO DE MUDAR O BRASIL, 2018) e "estímulo à prática de Educação Física nas escolas do ensino básico” (M2) (COLIGAÇÃO UNIDOS PARA TRANSFORMAR O BRASIL, 2018). Complementarmente, também cabe mencionar as estratégias voltadas aos investimentos na infraestrutura escolar, nas PG de Fernando Haddad (F4) (COLIGAÇÃO O POVO FELIZ DE NOVO, 2018) e Marina Silva (M2) (COLIGAÇÃO UNIDOS PARA TRANSFORMAR O BRASIL, 2018).

Considerando-se a atividade física no contexto do deslocamento, nas PG de Fernando Haddad (F8) (COLIGAÇÃO O POVO FELIZ DE NOVO, 2018) e Marina Silva (M3) (COLIGAÇÃO UNIDOS PARA TRANSFORMAR O BRASIL, 2018) foram identificadas açôes que visam a implementação de ciclovias e pistas de caminhadas/ corridas (quadro 2). No contexto comunitário, observamos na PG de Fernando Haddad a estratégia de incentivo a "atividade física e alimentação adequada, saudável e segura” (F9) (COLIGAÇÃO O POVO FELIZ DE NOVO, 2018) e na PG de Jair Bolsonaro o programa de "inclusão dos Profissionais de 
Educação Física no programa de Saúde da Família, com o objetivo de ativar as academias ao ar livre” (J1) (COLIGAÇÃO BRASIL ACIMA DE TUDO, DEUS ACIMA DE TODOS, 2018).

Quadro 2. Estratégias e seus respectivos tipos, em relação a temática Práticas Corporais/ Atividade Física, previstas nas propostas de governo presidenciais, Brasil, 2018.

\begin{tabular}{|c|c|c|}
\hline Código & Tipo & Estratégia \\
\hline \multicolumn{3}{|r|}{ Coligação Brasil soberano - Candidato: Ciro Gomes } \\
\hline $\mathrm{C} 1$ & Ação & "Implementação e qualificação do esporte na escola." \\
\hline $\mathrm{C} 2$ & Ação & "Promoção facilitada do acesso à cidade e espaços de lazer." \\
\hline \multicolumn{3}{|r|}{ Partido democracia cristã - Candidato: Eymael } \\
\hline E1 & Ação & $\begin{array}{l}\text { "Implantar o pró-amador - plano nacional de apoio ao esporte amador } \\
\text { competitivo [...] promovendo ainda políticas públicas para integraçáo da } \\
\text { criança e do adolescente na prática do esporte em suas várias modalidades." }\end{array}$ \\
\hline E2 & Ação & "Assegurar a todos, mediante políticas públicas específicas o direito ao lazer." \\
\hline \multicolumn{3}{|r|}{ Coligaçáo o povo feliz de novo - Candidato: Fernando Haddad } \\
\hline F1 & Ação & Promoçáo do "esporte escolar." \\
\hline $\mathrm{F} 2$ & Ação & $\begin{array}{l}\text { "Em regiôes de alta vulnerabilidade [...] As escolas serão abertas para as } \\
\text { respectivas comunidades e serão polos de cultura, esporte e lazer." }\end{array}$ \\
\hline F3 & Ação & $\begin{array}{l}\text { "Integração da política de esporte com as demais políticas públicas, o que } \\
\text { inclui o apoio aos municípios na criação de espaços livres para prática } \\
\text { espontânea de esporte pela população." }\end{array}$ \\
\hline F4 & Ação & $\begin{array}{l}\text { "Serão retomados os investimentos na infraestrutura de equipamentos } \\
\text { esportivos, sobretudo reforma e requalificação de quadras nas escolas. O foco } \\
\text { será nos equipamentos voltados às juventudes e na acessibilidade para pessoas } \\
\text { idosas e com deficiência." }\end{array}$ \\
\hline F5 & Ação & $\begin{array}{l}\text { "Investimento em todas as práticas esportivas, tais como vôlei, basquete, nataçáo } \\
\text { e esportes radicais, tanto no esporte amador quanto no de alto rendimento." }\end{array}$ \\
\hline F6 & Política & "Criação do Sistema Único do Esporte." \\
\hline F7 & Ação & $\begin{array}{l}\text { "Implementaçáo da "Universidade do Esporte, articulando ensino, pesquisa e } \\
\text { extensão." }\end{array}$ \\
\hline F8 & Ação & "Implantação de ciclovias." \\
\hline F9 & Ação & $\begin{array}{l}\text { "Elaboração de programas que incentivem a atividade física e alimentação } \\
\text { adequada, saudável e segura." }\end{array}$ \\
\hline
\end{tabular}




\begin{tabular}{|c|c|c|}
\hline Código & Tipo & Estratégia \\
\hline \multicolumn{3}{|c|}{ Coligação vamos sem medo de mudar o Brasil - Candidato Guilherme Boulos } \\
\hline G1 & Ação & $\begin{array}{l}\text { "Considerar os espaços públicos, campos, ginásios e quadras como lugares para } \\
\text { todos e todas se apropriarem." }\end{array}$ \\
\hline G2 & Política & "Criação do Sistema Nacional de Esporte e Lazer." \\
\hline G3 & Ação & $\begin{array}{l}\text { "Apoiar e fomentar projetos e programas de práticas corporais e de lazer que } \\
\text { não se restrinjam ao esporte de alto rendimento." }\end{array}$ \\
\hline G4 & Ação & "Promover jogos, torneios e lazer para a Terceira Idade." \\
\hline G5 & Ação & "Promover jogos, torneios e competições entre escolas." \\
\hline G6 & Ação & $\begin{array}{l}\text { "Garantir a participação dos movimentos LGBTIs (lésbicas, gays, bissexuais } \\
\text { e transgêneros) na formulação de programas e projetos de esporte, lazer e } \\
\text { práticas corporais." }\end{array}$ \\
\hline G7 & Ação & "Transformar Ministério do Esporte em Ministério do Esporte e Lazer." \\
\hline G8 & Ação & $\begin{array}{l}\text { "Realizar e atualizar permanentemente o Diagnóstico Nacional de Esporte e } \\
\text { Lazer, bem como fomentar a realizaçáo de diagnósticos estaduais, distrital e } \\
\text { municipais." }\end{array}$ \\
\hline G9 & Ação & $\begin{array}{l}\text { "Realizar a Conferência Nacional de Esporte e Lazer a cada dois anos e induzir a } \\
\text { realização de Conferências Livres, Regionais, Municipais, Distrital e estaduais." }\end{array}$ \\
\hline G10 & Ação & $\begin{array}{l}\text { "Fortalecer e ampliar a REDE CEDES (Centro de Desenvolvimento do } \\
\text { Esporte Recreativo e do Lazer)." }\end{array}$ \\
\hline G11 & Ação & $\begin{array}{l}\text { "Criar o Programa de Apoio às Pesquisas relacionadas ao desenvolvimento do } \\
\text { esporte e do lazer no Brasil, que envolva a Rede CEDES, a Rede CENESP e } \\
\text { criar o Centro de Desenvolvimento da Educaçáo Física Escolar." }\end{array}$ \\
\hline G12 & Política & $\begin{array}{l}\text { "Criar uma Política Nacional de Formação em Esporte e Lazer, que abranja os } \\
\text { diversos níveis de ensino (técnico, graduação e pós-graduação) para os diferentes } \\
\text { trabalhadores de esporte e lazer (gestores, professores, técnicos, ex-atletas e } \\
\text { agentes sociais) e programas sociais, vinculados às instituições formadoras." }\end{array}$ \\
\hline G13 & Ação & $\begin{array}{l}\text { "Estabelecer mecanismos de Monitoramento e Avaliação das Políticas de } \\
\text { Esporte e Lazer, garantindo transparência e controle social." }\end{array}$ \\
\hline G14 & Ação & $\begin{array}{l}\text { "Incluir a temática do Esporte e Lazer nas deliberaçôes do Sistema Nacional } \\
\text { de Democracia Direta [...] com a intervenção e deliberação da sociedade na } \\
\text { utilização dos recursos." }\end{array}$ \\
\hline
\end{tabular}

continua... 


\begin{tabular}{|c|c|c|}
\hline Código & Tipo & Estratégia \\
\hline G15 & Ação & $\begin{array}{l}\text { "Fomentar a constituição de Conselhos Comunitários para gestão dos } \\
\text { equipamentos públicos de esporte e lazer construídos, revitalizados e } \\
\text { qualificados nas cidades, incluindo programaçáo com oficinas e práticas } \\
\text { espontâneas de esporte e lazer gratuitas para a comunidade." }\end{array}$ \\
\hline G16 & Ação & $\begin{array}{l}\text { "Constituir um fundo público exclusivo do esporte e lazer, descentralizado e } \\
\text { com acompanhamento da sociedade civil." }\end{array}$ \\
\hline G17 & Ação & $\begin{array}{l}\text { "Destinar os gastos orçamentários prioritariamente para a garantia do esporte } \\
\text { e lazer como direito, nos programas de fomento a vivência esportiva com fins } \\
\text { educacionais e de participaçáo." }\end{array}$ \\
\hline G18 & Ação & $\begin{array}{l}\text { "Destinar os recursos extra-orçamentários de empresas estatais para a garantia } \\
\text { do esporte e lazer como direito e para a iniciaçáo e a excelência esportivas." }\end{array}$ \\
\hline G19 & Ação & $\begin{array}{l}\text { "Destinar } 5 \% \text { do total arrecadado pela venda coletiva e centralizada dos } \\
\text { direitos de transmissão a projetos sociais que promovam a prática do futebol, } \\
\text { bem como a centros de formação para o futebol feminino." }\end{array}$ \\
\hline \multicolumn{3}{|c|}{ Coligaçáo Brasil acima de tudo, Deus acima de todos - Candidato: Jair Bolsonaro } \\
\hline $\mathrm{J} 1$ & Programa & $\begin{array}{l}\text { "Inclusão dos Profissionais de Educação Física no programa de Saúde da } \\
\text { Família, com o objetivo de ativar as academias ao ar livre." }\end{array}$ \\
\hline \multicolumn{3}{|r|}{ Coligação unidos para transformar o Brasil-Candidata: Marina Silva } \\
\hline M1 & Ação & $\begin{array}{l}\text { "Apoio técnico e financeiro para que Estados e Municípios possam cumprir a } \\
\text { meta de oferecer espaço público adequado às PCAF para cada grupo de } 10 \text { mil } \\
\text { habitantes." }\end{array}$ \\
\hline M2 & Política & $\begin{array}{l}\text { "Educação Física nas escolas [...] oferecida por profissionais com licenciatura } \\
\text { na área e à ampliação da construção de quadras esportivas cobertas nas escolas } \\
\text { do ensino fundamental." }\end{array}$ \\
\hline M3 & Ação & $\begin{array}{l}\text { "Apoio aos municípios com mais de } 100 \text { mil habitantes a implantarem } \\
\text { ciclovias, pistas de corridas e caminhadas, que interliguem os espaços } \\
\text { residenciais e os comerciais, bem como a implementaçáo de políticas que } \\
\text { favoreçam o uso de vias públicas para a prática de atividade física." }\end{array}$ \\
\hline M4 & Ação & $\begin{array}{l}\text { "O problema da segurança pública [...] é, antes de tudo, uma questão de } \\
\text { segurança social. Uma política integrada, envolvendo educação, saúde, } \\
\text { esportes e cultura, será estabelecida com foco na valorização da vida e } \\
\text { prevençáo da violência." }\end{array}$ \\
\hline
\end{tabular}

No quadro 3, pode-se observar que nem todas as estratégias apresentaram respectivas intencionalidades. Cabe mencionar, dessa forma, que buscamos resgatar, para além das intencionalidades mais específicas em relação às 
estratégias, as intencionalidades mais gerais de cada PG em relação aos assuntos pertencentes a temática das PCAF.

No quadro 3, com olhar geral, a PG de Fernando Haddad justifica a promoção do esporte como "direito social", considerando seu potencial como "instrumento de formação educacional e integração social, que contribui para a convivência em comunidade e para a vida saudável", "um dos pilares constituintes da identidade brasileira" e que "permite a implementação de açôes transversais nas áreas de educação, saúde e segurança cidadã” (COLIGAÇÃO O POVO FELIZ DE NOVO, 2018). Na PG de Guilherme Boulos, o esporte e o lazer são vistos como direitos, mencionando "políticas públicas para a inclusão de setores populares preteridos e sua promoção "para que as pessoas possam viver melhor" (COLIGAÇÃO VAMOS SEM MEDO DE MUDAR O BRASIL, 2018). A PG de Marina Silva aponta "para que os brasileiros tenham acesso aos benefícios do esporte é fundamental garantir políticas públicas" (COLIGAÇÃO UNIDOS PARA TRANSFORMAR O BRASIL, 2018).

Quando atreladas às estratégias, percebemos olhares distintos em relação as intencionalidades na promoção do esporte recreativo: na PG de Ciro Gomes, a promoção do esporte escolar é fomentada enquanto "ferramenta de entretenimento e amparo aos jovens estudantes” (C1) (COLIGAÇÃO BRASIL SOBERANO, 2018), na PG de Eymael o porquê está em sua "importância na formação do caráter dos jovens e no combate as drogas” (E1) (PARTIDO DEMOCRACIA CRISTÃ, 2018), na PG de Fernando Haddad, um olhar mais geral, de "ser tratado como política de Estado" (F5) (COLIGAÇÃO O POVO FELIZ DE NOVO, 2018); Guilherme Boulos menciona democratização do acesso (G1) e garantia da "intersecção entre esporte e saúde” (G3) (COLIGAÇÃO VAMOS SEM MEDO DE MUDAR O BRASIL, 2018) (quadro 3).

No contexto comunitário, as estratégias de Fernando Haddad e Jair Bolsonaro apresentaram intencionalidades distintas. Na primeira, objetiva-se a "promoção da saúde” (F8) (COLIGAÇÃO O POVO FELIZ DE NOVO, 2018) e na segunda, o combate ao "sedentarismo e a obesidade e suas graves consequências à população como AVC [Acidente Vascular Cerebral - grifo nosso] e infarto do miocárdio" (J1) (COLIGAÇÃO BRASIL ACIMA DE TUDO, DEUS ACIMA DE TODOS, 2018). A PG de Fernando Haddad também menciona a "implementação de ciclovias" como meio para melhoria da "mobilidade" (F7) (COLIGAÇÃO O POVO FELIZ DE NOVO, 2018) (Quadro 3). 
Quadro 3. Intencionalidades, na temática das Práticas Corporais/ Atividade Física, previstas nas propostas de governo presidenciais, Brasil, 2018.

\begin{tabular}{|c|c|}
\hline Código & Intencionalidade(s) \\
\hline \multicolumn{2}{|r|}{ Coligação Brasil soberano - Candidato: Ciro Gomes } \\
\hline $\mathrm{C} 1$ & "Ferramenta de entretenimento e amparo aos jovens estudantes" \\
\hline $\mathrm{C} 2$ & "Para que os jovens possam viver a cidade em sua plenitude" \\
\hline \multicolumn{2}{|r|}{ Partido democracia cristã - Candidato: Eymael } \\
\hline E1 & $\begin{array}{l}\text { Reconhecimento de sua "importância na formação do caráter dos jovens e no combate as } \\
\text { drogas" }\end{array}$ \\
\hline E2 & "Forma de promoção social" \\
\hline \multicolumn{2}{|r|}{ Coligação o povo feliz de novo - Candidato: Fernando Haddad } \\
\hline $\mathrm{nr}$ & $\begin{array}{l}\text { "O esporte é um direito social previsto em nossa Constituição. Como instrumento } \\
\text { de formação educacional e integração social, que contribui para a convivência em } \\
\text { comunidade e para a vida saudável, o esporte constrói a cidadania. Como manifestaçáo } \\
\text { cultural é um dos pilares constituintes da identidade brasileira. É também uma potente } \\
\text { âncora econômica, com força para gerar riquezas e empregos, sendo historicamente um } \\
\text { importante fator de desenvolvimento social e inserção das minorias. Sua capacidade de } \\
\text { mobilizar crianças, adolescentes e jovens permite a implementação de ações transversais } \\
\text { nas áreas de educação, saúde e segurança cidadã." }\end{array}$ \\
\hline F5 & $\begin{array}{l}\text { "Nosso programa de governo entende que o desenvolvimento do esporte deve ser tratado } \\
\text { como política de Estado" }\end{array}$ \\
\hline F6 & $\begin{array}{l}\text { "Formação de profissionais de nível internacional voltados para toda a cadeia produtiva do } \\
\text { esporte (gestáo esportiva, saúde, pesquisa e políticas públicas." }\end{array}$ \\
\hline F7 & "Mobilidade" \\
\hline F8 & "Promoção da saúde" \\
\hline \multicolumn{2}{|r|}{ Coligação vamos sem medo de mudar o Brasil-Candidato Guilherme Boulos } \\
\hline $\mathrm{nr}$ & $\begin{array}{l}\text { "Esporte e Lazer são direitos porque são necessidades humanas e, assim, devem incumbir o } \\
\text { Estado a desenvolver políticas públicas que garantam o acesso da população." }\end{array}$ \\
\hline $\mathrm{nr}$ & $\begin{array}{l}\text { "Priorizar os esportes de alto rendimento, sobretudo as competiçôes, naturalizam } \\
\text { desigualdades e reforçam relaçôes de dominação social. Sem negligenciar a importância } \\
\text { dos grandes atletas, que possuem suas demandas legítimas, é necessário valorizar outras } \\
\text { práticas, reconhecendo a oportunidade de reverter a razão normativa que estabelece a } \\
\text { inferiorização dos corpos das mulheres, que inibe a livre expressão da diversidade sexual, } \\
\text { que reprime violentamente a presença de pessoas transgêneras e intersexuais e que reforça } \\
\text { estigmas racistas." }\end{array}$ \\
\hline
\end{tabular}




\begin{tabular}{|c|c|}
\hline Código & Intencionalidade(s) \\
\hline $\mathrm{nr}$ & $\begin{array}{l}\text { Reposicionar "as políticas públicas para a inclusão de setores populares preteridos, tanto } \\
\text { socialmente quanto pela hegemonia sexista dos corpos atléticos e pelos esportes de alto } \\
\text { rendimento, altamente lucrativos para a iniciativa privada." }\end{array}$ \\
\hline $\mathrm{nr}$ & $\begin{array}{l}\text { "Para que as pessoas possam viver melhor, tendo seus corpos como autônomos, fortalecidos } \\
\text { e livres" }\end{array}$ \\
\hline G1 & "Democratizar o acesso ao esporte e às práticas corporais" \\
\hline G3 & $\begin{array}{l}\text { "Garantir a intersecção entre esporte e saúde, ampliando o PELC (Programa de Esporte e } \\
\text { Lazer na Cidade) e estimulando a organização e o reconhecimento de núcleos comunitários } \\
\text { e seus atores locais." }\end{array}$ \\
\hline G4 & "Incentivar o esporte lazer e sociabilidades no ambiente escolar." \\
\hline & Coligação Brasil acima de tudo, Deus acima de todos - Candidato: Jair Bolsonaro \\
\hline $\mathrm{J} 1$ & $\begin{array}{l}\text { "Meio de combater o sedentarismo e a obesidade e suas graves consequências à população } \\
\text { como AVC e infarto do miocárdio." }\end{array}$ \\
\hline & Coligação unidos para transformar o Brasil-Candidata: Marina Silva \\
\hline $\mathrm{nr}$ & $\begin{array}{l}\text { "Para que os brasileiros tenham acesso aos benefícios do esporte é fundamental garantir } \\
\text { políticas públicas para incentivar a educaçáo física nas escolas, as práticas do esporte e } \\
\text { de atividades físicas para a populaçáo jovem, adulta e idosa e promover o esporte de alto } \\
\text { rendimento." }\end{array}$ \\
\hline
\end{tabular}

Legenda: AVC: acidente vascular cerebral; $n$ r: intencionalidade não relacionada a nenhuma estratégia de forma específica

\section{Discussão}

Em uma perspectiva geral, destacamos a ausência de estratégias voltadas à temática das PCAF em mais da metade das PG dos(as) candidatos à presidência da república do Brasil de 2018, assim como importantes diferenças nas estratégias e intencionalidades analisadas. $\mathrm{O}$ fato de sete das 13 PG não apresentarem mençóes na temática das PCAF é um resultado que chamou a atenção, ora pelo fato de a atividade física ser preconizada por lei como "fator determinante e condicionante da saúde" na legislação do Sistema Único de Saúde (SUS) (BRASIL, 2013b), ora pela sua crescente incorporação nas políticas nacionais de saúde nos últimos anos (BRASIL 2013a; BRASIL, 2014; SÁ et al., 2016; LOCH et al., 2018; BRASIL, 2019).

Quanto aos tipos de estratégias, a maior parte delas foi classificada como açóes - potencialmente ligadas às políticas de governo - provavelmente considerando que 
haveria maior governabilidade para executá-las. Por exemplo, das quatro estratégias classificadas como políticas (F6, G2, G12, M2) (COLIGAÇÃO O POVO FELIZ DE NOVO, 2018; COLIGAÇÃO VAMOS SEM MEDO DE MUDAR O BRASIL, 2018; COLIGAÇÃO UNIDOS PARA TRANSFORMAR O BRASIL, 2018), três eram relacionadas ao Sistema Nacional de Esporte. Em particular, muitas estratégias propostas pareciam estar mais no campo da articulação política ou de ações que já acontecem rotineiramente.

Também, para que se tornem realidade, é importante que estas estratégias estejam previstas no Plano Plurianual, Lei de Diretrizes Orçamentarias e na Lei Orçamentaria Anual. Além disso, se acresce o baixo orçamento destinado ao setor esporte, incluindo o extinto Ministério do Esporte, que entre o período de 2001 e 2012 apresentou uma variação de participação em relação ao PIB de 0,01\% a 0,05\%, sendo o período mais alto entre 2006 e 2011, correspondente ao período de organização dos megaeventos esportivos no Brasil (MASCARENHAS, 2016).

O tema "esporte recreativo" recebeu maior número de mençôes possivelmente, por conta da sua tradição no contexto nacional da Educação Física e pelo Brasil recentemente ter sediado os principais megaeventos esportivos mundiais. Entretanto, merece destaque a ampla variedade de estratégias mencionadas, que abrangem desde o fortalecimento sistêmico do esporte (F6, G2) (COLIGAÇÃO O POVO FELIZ DE NOVO, 2018; COLIGAÇÃO VAMOS SEM MEDO DE MUDAR O BRASIL, 2018), acampando todas as suas dimensóes e permitindo a inclusão social, até propostas pouco plausíveis, como a do investimento em "todas as práticas esportivas, tais como vôlei, basquete, natação e esportes radicais, tanto no esporte amador quanto no de alto rendimento" (F5) (COLIGAÇÃO O POVO FELIZ DE NOVO, 2018).

É possível que esta última ação mencionada (F5) (COLIGAÇÃO O POVO FELIZ DE NOVO, 2018) tenha sido idealizada no sentido de romper com certa "monocultura" do Futebol, que, apesar de ter apresentando redução no seu número de participantes na sua forma recreativa (LIMA; PIOVANI; LIMA, 2018), ainda tem grande hegemonia na cobertura midiática. Percebemos que o alcance desta estratégia seria praticamente impossível, considerando-se a amplitude do que seriam "todos os esportes" e por não fazer sentido - pelo menos em relação à promoção da atividade física - investir em esportes sem identificação com a cultura brasileira, cuja prática seria simplesmente inviável (ex. modalidades típicas de países muito frios e 
que necessitam de alto volume de neve para serem praticados) ou mesmo porque é no mínimo questionável se faz sentido investir em esportes que envolvem custos elevados e poucos praticantes por "equipamento", como vela e hipismo, por exemplo.

Não discordamos sobre o quão importante seria a promoção de distintas modalidades esportivas no país, desde a experimentação/ prática recreativa até o alto rendimento, mas além da dificuldade expressada no parágrafo anterior, a literatura sugere que recentemente menores orçamentos foram conferidos aos gastos diretos com a prática esportiva, no sentido de garantir o acesso ao esporte (CARNEIRO; ATHAYDE; MASCARENHAS, 2019; CARNEIRO et al., 2019). Assim sendo, acreditamos que a promoção do esporte recreativo, no sentido da ampliação da oferta e dos acessos perpasse, não apenas pelas propostas de candidaturas, mas por uma mudança no direcionamento dos orçamentos/ gastos, que nos últimos anos vêm atendendo mais aos interesses econômicos (SILVA; BORGES; AMARAL; 2015; CARNEIRO; ATHAYDE; MASCARENHAS, 2019; CARNEIRO et al., 2019).

A presente síntese apontou distintas intencionalidades conferidas ao esporte de recreaçâo, considerando-se olhares mais ampliados que o entendem como um "direito social" previsto na Constituição (F-nr), elemento de construção da cidadania (F-nr) e, no sentido cultural, "um dos pilares constituintes da identidade brasileira" (F-nr) (COLIGAÇÃO O POVO FELIZ DE NOVO, 2018). Também foram identificadas intencionalidades que apontam a necessidade do reposicionamento das "políticas públicas para a inclusão de setores populares preteridos" (G-nr), garantia de "intersecção entre esporte e saúde (G3) (COLIGAÇÃO VAMOS SEM MEDO DE MUDAR O BRASIL, 2018), até o reconhecimento de sua "importância na formação do caráter dos jovens e no combate as drogas" (E1) (PARTIDO DEMOCRACIA CRISTÁ, 2018).

Embora a abordagem "salvacionista" do esporte, que muitas vezes considera o esporte como uma panaceia, não seja exclusiva na PG de Eymael, visto que o documento deste candidato também aborda outros aspectos da temática das PCAF, como o "incentivo ao lazer, por parte do poder público", com intencionalidade de "desenvolvimento social", é de se reconhecer que a visão "salvacionista" está historicamente incutida no imaginário social do país, sendo comumente revisitada e reforçada em distintas oportunidades e contextos (RODRIGUES, 2008).

De qualquer forma, sem evidentemente ignorar que o esporte pode auxiliar neste cenário, reforçamos que estratégias de proteçấo à vida dos jovens brasileiros 
devam ser compreendidas e aprofundadas em sua complexidade e, nesse sentido, implementadas por meio de açóes intra e intersetoriais, indo para além de estratégias que visem exclusivamente a ampliação do acesso ao esporte ou PCAF de uma forma mais geral (ROMERA, 2013). Nesse caso, as PG de Fernando Haddad, ao mencionar a "integração do esporte com as demais políticas públicas" (F3) (COLIGAÇÃO O POVO FELIZ DE NOVO, 2018) e de Marina Silva remetem a uma visão mais ampla para o enfrentamento deste problema, percebendo a necessidade da criação e fortalecimento de "uma política integrada, envolvendo educação, saúde, esportes e cultura [...] com foco na valorização da vida e prevenção da violência” (M4) (COLIGAÇÃO UNIDOS PARA TRANSFORMAR, 2018).

Em relação à promoção de PCAF no ambiente escolar (C1, F1, F2, F4, G5, G11, M2) (COLIGAÇÃO BRASIL SOBERANO, 2018; COLIGAÇÃO O POVO FELIZ DE NOVO, 2018; COLIGAÇÃO VAMOS SEM MEDO DE MUDAR O BRASIL, 2018; COLIGAÇÃO UNIDOS PARA TRANSFORMAR O BRASIL, 2018), foram identificadas estratégias que partem desde a criação do "Centro de Desenvolvimento da Educação Física Escolar" (G11) (COLIGAÇÃO VAMOS SEM MEDO DE MUDAR O BRASIL, 2018) até a abertura de escolas para a comunidade, colocando-se como "polos de cultura, esporte e lazer" (F2) (COLIGAÇÃO O POVO FELIZ DE NOVO, 2018). Complementarmente, cabe destacar as estratégias que se propuseram à "ampliação da construção de quadras esportivas cobertas nas escolas do ensino fundamental" (M2) (COLIGAÇÃO UNIDOS PARA TRANSFORMAR O BRASIL, 2018) e "reforma e requalificação" de quadras poliesportivas na escola (F4) (COLIGAÇÃO O POVO FELIZ DE NOVO, 2018), possivelmente pelo reconhecimento das estruturas deficitárias das escolas para as práticas esportivas (IBGE, 2017).

O relatório do PNUD (2017) indica as atividades físicas e esportivas como elemento central de um novo modelo de escola ("Escola Ativa”), em um processo que envolve toda a comunidade escolar. Dessa forma, investimentos na construção e manutenção dos espaços (para além das quadras) fazem parte desta proposta de escola. Esse modelo caminha para além dos conhecimentos e práticas da Educação Física, de modo que o espaço escolar possa ser um local de acesso às várias possibilidades de práticas, abrangendo distintas faixas etárias, como, por exemplo, em estratégias que promovam sua abertura para a comunidade aos finais de semana. Por outro lado, percebendo que no país há o declínio da prevalência de indivíduos fisicamente 
ativos ao longo do envelhecimento (FLORINDO et al., 2009; SILVA et al., 2014), é também importante que estas estratégias não sejam restritas às escolas/ alunos de ensino fundamental, tal como preconiza a política proposta por Marina Silva (M2) (COLIGAÇÃO UNIDOS PARA TRANSFORMAR O BRASIL, 2018).

A "implantação de ciclovias" (F8, M3) (COLIGAÇÃO O POVO FELIZ DE NOVO, 2018; COLIGAÇÃO UNIDOS PARA TRANSFORMAR O BRASIL, 2018) e de pistas de corridas e caminhadas, que interliguem os espaços residenciais e os comerciais, bem como a implementação de políticas que favoreçam o uso de vias públicas para a prática de atividade física" (M3) (COLIGAÇÃO UNIDOS PARA TRANSFORMAR O BRASIL, 2018) são estratégias que dialogam com a questão da mobilidade urbana - embora essa intencionalidade fora especificada apenas na PG de Fernando Haddad (COLIGAÇÃO O POVO FELIZ DE NOVO, 2018) de modo que se torne possível o diálogo e a elaboração de estratégias intersetoriais, como nos casos do Estatuto da Cidade (BRASIL, 2008(a)) e o Plano Nacional de Mobilidade (BRASIL, 2012).

Duas estratégias abordam o contexto comunitário: F9 e J1 (COLIGAÇÃO BRASIL ACIMA DE TUDO, DEUS ACIMA DE TODOS, 2018; COLIGAÇÃO O POVO FELIZ DE NOVO, 2018). A primeira, mais genérica, propõe a "elaboração de programas que incentivem a atividade física e alimentação adequada, saudável e segura" (F9), tendo como intencionalidade a "promoção da saúde" (COLIGAÇÃO O POVO FELIZ DE NOVO, 2018). Sobre a segunda, mais específica, prevendo a "inclusão dos Profissionais de Educação Física no programa de Saúde da Família, com o objetivo de ativar as academias ao ar livre" (J1) (COLIGAÇÃO BRASIL ACIMA DE TUDO, DEUS ACIMA DE TODOS, 2018), mesmo que tenha sido a única estratégia que especificou temática das PCAF no contexto do SUS, ela acena para algo que já existe, considerando-se que a possibilidade de introdução deste profissional no SUS pode ocorrer desde 2008, quando foram criados os Núcleos Ampliado à Saúde da Família (BRASIL, 2008b). Ademais, chama a atenção nesta proposta o entendimento restrito sobre a atuação do profissional de Educação Física (pois trata da "inclusão" de profissionais e não da ampliação dos seus espaços e/ ou possibilidades de atuação), náo mencionando que sua atuação pode - e deve - ir muito além disso, inclusive fazendo parte das equipes multiprofissionais e atuando de maneira interprofissional, nas consultas compartilhadas, por exemplo (BRASIL, 2009; LOCH; DIAS; RECH; 2019). 
Por outro lado, a visão restrita também se alonga para a sua intencionalidade, no sentido de "combater o sedentarismo e a obesidade e suas graves consequências à população como AVC e infarto do miocárdio" (COLIGAÇÃO BRASIL ACIMA DE TUDO, DEUS ACIMA DE TODOS, 2018), ao passo que o olhar ampliado da promoção da saúde (em paralelo ao olhar mais restrito da prevenção de doenças) seja preconizado como o principal elemento de ação no contexto da atenção básica nacional (BRASIL, 2014).

Em vista dos rumos atuais do debate na temática das PCAF, percebemos que nenhuma PG/ estratégia a abordou de maneira mais direta a questão do desenvolvimento humano, estando distantes do que se aponta no relatório do PNUD (2017), produzido por representantes das universidades e profissionais que atuam na promoção das PCAF no Brasil e que está articulado aos objetivos e metas de desenvolvimento sustentável da Organização Mundial da Saúde para 2030 (OMS, 2018).

Outro aspecto pouco mencionado nas PG, pelo menos de maneira literal, é o desafio da diminuição das iniquidades para o acesso à atividade física, uma vez que existem importantes evidências indicando que sua prática, especialmente no contexto do tempo de lazer, está associada à importantes variáveis sociodemográficas, como renda (SILVA et al., 2014; DEL DUCA et al., 2013), cor da pele (DEL DUCA et al., 2013), sexo (BARBOSA FILHO; CAMPOS; LOPES, 2014; DEL DUCA et al., 2013; FLORINDO et al., 2009; SILVA et al., 2014) e idade (DEL DUCA et al., 2013; FLORINDO et al., 2009; SILVA et al., 2014), havendo importantes diferenças entre os subgrupos, conforme estas características, sendo urgente o enfrentamento destas desigualdades.

A não-avaliação das estratégias e intencionalidades relativas à temática das PCAF com outras estratégias propostas pode ser mencionada como uma importante limitação do presente trabalho, inclusive para se oferecer uma avaliação mais ampla das suas coerências e incoerências quanto a outros temas mais estruturantes ao Estado, como saúde, educação, segurança pública e mobilidade.

\section{Considerações finais}

Sete das 13 PG presidenciais analisadas não apresentaram propostas para a promoção das PCAF no país, o que é um número bastante elevado se considerarmos os grandes avanços que a temática das PCAF teve nos últimos anos no Brasil, 
inclusive em um contexto em que existem importantes políticas públicas. A não abordagem deste tema nas $\mathrm{PG}$ nos parece ser um indicativo de que o acesso às PCAF como um direito fundamental das pessoas ainda não é plenamente reconhecido no país. Ademais, em vista da maior frequência de propostas para a promoção do esporte recreativo, do ambiente escolar e do ambiente construído, respectivamente, observamos que as PG que abordam o tema diferem bastante tanto em relação as estratégias para sua promoção, quanto sobre suas intencionalidades, o que é compreensível, pois existem muitas maneiras de se promover as PCAF e que estas podem ter diferentes objetivos, inclusive em função da sua natureza intersetorial.

Nesse sentido, mesmo que o tema PCAF tenha sido englobado por PG de correntes políticas distintas, é ingênuo achar que as propostas são iguais ou que as PCAF podem ser um elemento para se "unir" estas diferentes correntes políticas - que representam distintas visóes de mundo - simplesmente porque as PG mencionam o objetivo de promoção destas práticas. As estratégias (o "como" promover as PCAF) e as intencionalidades (os "porquês" de se promover estas práticas) diferiram bastante entre as PG.

Concluindo, diante das diferenças conceituais e nas intençôes das ações, planos e políticas públicas propostas nas PG presidenciais, nossos resultados chamam a atenção para a importância de análises mais criteriosas na avaliação das propostas relacionadas ao tema, indo para além do mero "citou" (ou não) a questão, uma vez que a promoção das PCAF pode "servir" a diferentes projetos de país. ${ }^{2}$

\section{Referências}

AMORIM, T; et al. Descriçấo dos programas municipais de promoção da atividade física financiados pelo Ministério da Saúde. Revista Brasileira de Atividade Física \& Saúde, v. 18, p. 63-74, 2013.

BARBOSA FILHO, V. C.; CAMPOS W.; LOPES, A. S. Epidemiology of physical inactivity, sedentary behaviors, and unhealthy eating habits among Brazilian adolescents: a systematic review. Ciência \& Saúde Coletiva, v. 19, p. 173-193, 2014.

BARROS, A. T. A governança ambiental nos planos de governo dos presidenciáveis nas eleiçôes de 2014. Revista Brasileira de Ciência Política, v. 23, p. 181-216.

BRACHT, V. Educação Física e Ciência: cenas de um casamento (in)feliz. Revista Brasileira de Ciências do Esporte, v. 22, p. 53-65, 2000. 
BRASIL. Lei $n^{o}$ 12.587, de 03 de Janeiro 2012. Institui as diretrizes da Política Nacional de Mobilidade Urbana. Brasília, 2012.

. Lei $n^{\circ} 12.864$, de 24 de setembro de 2013. Altera o caput do art. $3^{\circ}$ da Lei $n^{\circ} 8.080$, de 19 de setembro de 1990, incluindo a atividade física como fator determinante e condicionante da saúde. Brasília, 2013b.

. Lei no 9.504, de 30 de setembro de 1997. Estabelece normas para as eleiçóes. Brasília, 1997.

. Ministério da Saúde. Decreto no 9.795, de 17 de maio de 2019. Aprova a Estrutura Regimental e o Quadro Demonstrativo dos Cargos em Comissão e das Funçôes de Confiança do Ministério da Saúde, remaneja cargos em comissão e funçôes de confiança, transforma funçóes de confiança e substitui cargos em comissão do Grupo-Direção e Assessoramento Superiores - DAS por Funçóes Comissionadas do Poder Executivo - FCPE. Brasília, 2019.

- Ministério da Saúde. Portaria no 2.446, de 11 de novembro de 2014. Redefine a Política Nacional de Promoção da Saúde (PNPS). Brasília: MS, 2014.

. Ministério da Saúde. Secretaria de Atenção à Saúde. Departamento de Atenção Básica. Saúde na escola. Série B. Textos Básicos de Saúde; Cadernos de Atenção Básica n. 27. Brasília: MS, 2009.

- Portaria $n^{\circ} 154$, de 24 de janeiro de 2008. Cria os Núcleos de Apoio à Saúde da Família - NASF. Brasília: MS, 2008b.

- Portaria $n^{\circ}$ 2.681, de 7 de novembro de 2013. Redefine o Programa Academia da Saúde no âmbito do Sistema Único de Saúde (SUS). Brasília: MS, 2013a.

. Senado Federal. Subsecretaria de Edições Técnicas. Estatuto da Cidade. 3 ed. Brasília, 2008.

CARNEIRO, F. H. S.; ATHAYDE, P. F. A.; MASCARENHAS, F. Era uma vez um ministério do esporte...: seu financiamento e gasto nos governos Lula, Dilma e Temer. Motrivivência, v. 31, n. 60, p. 1-22, 2019.

CARNEIRO, F. H. S. et al. Orçamento do esporte no governo Dilma: a primazia dos interesses econômicos e o direito escanteado. Revista Brasileira de Ciências do Esporte. v. 41, p. 343-349, 2019.

CARVAlHO, F. F. B.; NOGUEIRA; J. A. D. Práticas corporais e atividades físicas na perspectiva da Promoção da Saúde na Atenção Básica. Ciência \& Saúde Coletiva, v. 21, p. 18291838, 2016.

CASTELLANI FILHO, L. Educação Física no Brasil: a história que não se conta. Campinas: Papirus, 1988. 
COLIGAÇÃO BRASIL ACIMA DE TUDO, DEUS ACIMA DE TODOS. Proposta de plano de governo da coligação Brasil acima de tudo, Deus acima de todos. 2018. Disponível em: http:// www.tse.jus.br/arquivos/jair-bolsonaro-proposta-de-governo-1o-turno (10 turno) e em: http:// divulgacandcontas.tse.jus.br/candidaturas/oficial/2018/BR/BR/2022802018/280000614517/ proposta_1534284632231.pdf. Acesso em: 09 jul. 2019.

COLIGAÇÃO BRASIL SOBERANO. Diretrizes para uma estratégia nacional de desenvolvimento para o Brasil. 2018. Disponível em: http://divulgacandcontas.tse.jus.br/candidaturas/ oficial/2018/BR/BR/2022802018/280000605589/proposta_1533938913830.pdf. Acesso em: 09 jul. 2019.

COLIGAÇÃO O POVO FELIZ DE NOVO. Plano de governo da coligação o povo feliz de novo. 2018. Disponível em: http://www.tse.jus.br/arquivos/fernando-haddad-proposta-de-governolo-turno (1o turno) e em: http://divulgacandcontas.tse.jus.br/candidaturas/oficial/2018/BR/ BR/2022802018/280028000062/proposta_1536702143353.pdf(2º turno). Acesso em: 09 jul. 2019. COLIGAÇÃO UNIDOS PARA TRANSFORMAR O BRASIL. Proposta de governo da coligaçâo unidos para transformar o Brasil. 2018. Disponível em: http://divulgacandcontas.tse.jus. br/candidaturas/oficial/2018/BR/BR/2022802018/280000622171/proposta_1535040841979. pdf. Acesso em: 09 jul. 2019.

COLIGAÇÃO VAMOS SEM MEDO DE MUDAR O BRASIL. Plano de governo da coligação vamos sem medo de mudar o Brasil. 2018. Disponível em: http://divulgacandcontas.tse.jus.br/ candidaturas/oficial/2018/BR/BR/2022802018/280000601016/proposta_1533565462424. pdf. Acesso em: 09 jul. 2019.

DAMICO, J.; KNUTH, A. G. O (des)encontro entre as práticas corporais e a atividade física: hibridizaçôes e borramentos no campo da saúde. Movimento, v. 20, p. 329-350, 2014.

DEL DUCA, G. F. et al. Prevalence and sociodemographic correlates of all domains of physical activity in Brazilian adults. Preventive Medicine, v. 56, p. 99-102, 2013.

FLORINDO, A. A. et al. Practice of physical activities and associated factors in adults, Brazil, 2006. Revista de Saude Publica, v. 43(supl 2), p. 65-73, 2009.

GOMES, R. Análise e Interpretação de dados em Pesquisa Qualitativa. In: DESLANDES, S. F. et al. (Orgs.). Pesquisa social: teoria, método e criatividade. 29.ed. Petrópolis: Vozes, 2010.

GONZÁLES, F. J.; FENSTERSEIFER, P. E. Dicionário Crítico de Educação Física. 2a ed. Ijuí: Editora Unijuí, 2008.

HALLAL, P. C. Atividade física e saúde no Brasil: pesquisa, vigilância e políticas. Cadernos de Saúde Pública, v. 30, p. 2487-2489, 2014.

INSTITUTO BRASILEIRO DE GEOGRAFIA E ESTATISTICA. Perfil dos estados e dos municipios brasileiros: esporte: 2016. Rio de Janeiro: IBGE, 2017. 
LIMA, D. F.; PIOVANI, V. G.S.; LIMA, L. A. Prática de futebol recreativo entre adultos residentes nas capitais brasileiras, 2011-2015. Epidemiologia \& Serviços de Saúde, v. 27, p. e2017284, 2018.

LOCH, M. R. et al. As práticas corporais/atividade física nos 30 anos do Sistema Único de Saúde. Ciência \& Saúde Coletiva, v. 23, p. 3469, 2018.

LOCH, M. R.; DIAS, D. F.; RECH, C. R. Apontamentos para a atuação do Profissional de Educação Física na Atenção Básica à Saúde: um ensaio. Revista Brasileira de Atividade Física \& Saúde, v. 24, e0069, 2019.

MALTA, D. C. et al. Política Nacional de Promoção da Saúde, descrição da implementação do eixo atividade física e práticas corporais, 2006 a 2014. Revista Brasileira de Atividade Física \& Saúde, v. 19, p. 286-299, 2014.

MANOEL, E. J.; CARVALHO, Y. M. Pós-graduação na Educação Física brasileira: a atração (fatal) para a biodinâmica. Educação e Pesquisa, v. 37, p. 389-406, 2011

MASCARENHAS, F. O orçamento do esporte: aspectos da atuação estatal de FHC a Dilma. Revista Brasileira de Educaçâo Física \& Esporte, v. 30, p. 963-980, 2016.

MATIAS, J. C.; BARROS, J. A. As políticas sociais nos planos de governo dos presidenciáveis 2018 no Brasil e a mídia. Revista de Políticas Públicas, v. 23, p. 339-355, 2019.

MATSUDO, V. et al. Promotion of physical activity in a developing country: the Agita São Paulo experience. Public Health Nutrition, v. 5, n. 1A, p. 253-61, 2002.

ORGANIZAÇÃO MUNDIAL DA SAÚDE. Global action plan on physical activity 20182030: more active people for a healthier world. Genebra: OMS, 2018.

PARTIDO DEMOCRACIA CRISTÃ. Diretrizes gerais de governo para construir um novo e melhor Brasil. 2018. Disponível em http://divulgacandcontas.tse.jus.br/candidaturas/oficial/2018/ BR/BR/2022802018/280000624085/proposta_1534450200223.pdf. Acesso em: 09 jul. 2019.

PROGRAMA DAS NAÇÓES UNIDAS PARA O DESENVOLVIMENTO. Relatório de Desenvolvimento Humano Nacional - Movimento é Vida: Atividades Físicas e Esportivas para Todas as Pessoas: 2017. Brasília: PNUD-OMS;2017. Disponível em: http://movimentoevida. org/wp-content/uploads/2017/09/PNUD_RNDH_completo.pdf. Acesso em: 09 jul. 2019.

RODRIGUES, A. L. A desportivização das politicas sociais para a juventude: discursos salvacionistas e práticas compensatórias. Porto Alegre: Pontifícia Universidade Católica do Rio Grande do Sul, 2008.

ROMERA, L. A. Esporte, lazer e prevenção ao uso de drogas. Licere. v. 16, 2013.

SÁ G. B. A. R. et al. O Programa Academia da Saúde como estratégia de promoção da saúde e modos de vida saudáveis: cenário nacional de implementação. Ciência \& Saúde Coletiva, v.21, p.1849-1860, 2016. 
SÁ-SILVA, J. R.; ALMEIDA, C. D.; GUINDANI, J. F. Pesquisa documental: pistas teóricas e metodológicas. Revista Brasileira de História \& Ciências Sociais, v. 1, p. 1-15, 2009.

SILVA, I. C. et al. Physical activity levels in three Brazilian birth cohorts as assessed with raw triaxial wrist accelerometry. International Journal of Epidemiology, v. 43, p. 1959-1968, 2014.

SILVA, D. S.; BORGES, C. N. F.; AMARAL, S. C. F. Gestão das políticas públicas do Ministério do Esporte do Brasil. Revista Brasileira de Educação Física e Esporte, v. 29, p. 65-79, 2015.

SORIANO, E. et al. Avaliação de propostas de candidatos a prefeitos em relação aos riscos de desastres naturais. Sociedade \& Natureza, v. 25, n. 3, p. 525-542, 2013.

SOUZA, L. K. Pesquisa com análise qualitativa de dados: conhecendo a Análise Temática. Arquivos Brasileiros de Psicologia, v. 71, p. 51-67, 2019.

TRAJANO, S. S.; MARQUES, A. A. V.; MARQUESAN, F. F. S. O discurso da sustentabilidade nos planos de governo dos presidenciáveis de 2014 no Brasil. Encontro Internacional sobre Gestão Empresarial e Meio Ambiente., XIX. Anais... 2017. Disponível em: http://engemausp.submissao. com.br/19/anais/arquivos/362.pdf. Acesso em: 09 jul. 2019.

\section{Notas}

${ }^{1}$ link: http://www.tse.jus.br/eleicoes/eleicoes-2018/propostas-de-candidatos

${ }^{2}$ P. H. Guerra: levantamento e análise dos dados; desenvolvimento e revisão do texto. D. R. Andrade: análise dos dados; desenvolvimento e revisão do texto. M. R. Loch: concepção da ideia central da pesquisa; análise dos dados; desenvolvimento e revisão do texto. 


\section{Abstract}

\section{Body practices/ physical activity promotion in Brazilian presidential government programs (2018): different proposals, different goals} This study sought to identify strategies and intentions related to the promotion of bodily practices / physical activity (PCAF) in presidential government (PG) proposals (2018). In possession of the PG, we performed readings and searches for terms related to the PCAF theme. For data analysis, we used elements of thematic content analysis. In only six (46.2\%) of the 13 deferred GPs, mentions to PCAF were found. In five PG we identified strategies related to recreational sport and in four to PCAF in the school environment. As for the intentions, we can see from those more linked to the improvement of clinical aspects of health and coping with drug use to those that assume the understanding of the access to the PCAF as a right for all. We conclude that access to PCAF is still not recognized as a right of all people, since more than half of the GPs do not even mention the topic and that the GPs that addressed this issue differed quite so much in relation to their strategies and intentions for their promotion, indicating that the discourse on the promotion of PCAF may apply to different country projects, and thus requires careful analysis of their paths and intentions.

> Keywords: motor activity; public policy; democracy; government programs. 